\title{
Comparative study of maximum power point tracking algorithms for wind turbine using permanent magnet synchronous generator
}

\author{
Huynh Quang Minh, Nguyen Van Liem
}

\begin{abstract}
Wind power is more and more developed as a renewable energy source. It is very essential to extract the maximum available power from the wind by operating the wind turbine at its optimal operating condition, called maximum power point tracking (MPPT). Perturb \& Observe (P\&O) is the simplest and mostly used algorithm for this purpose. However, this algorithm has its own disadvantages such as oscillation at maximum power point and wrong directionality under fast variation wind speed. Lots of publications are presented to solve these problems. In this paper, a conventional P\&O algorithm, a modified MPPT algorithm and a fuzzy MPPT algorithm for variable speed wind turbine using permanent magnet synchronous generator (PMSG) are tested and compared in the terms of complexity, speed responses and the ability to acquire the maximal energy output.
\end{abstract}

Index Terms - wind turbine, permanent magnet synchronous generator, maximum power point tracking, perturb and observe, modified algorithm, fuzzy controller.

Manuscript Received on March 15 ${ }^{\text {th }}$, 2017, Manuscript Revised on November $01^{\text {st }}, 2017$.

This research is funded by Vietnam National University Ho Chi Minh City (VNU-HCM) under grant number C2016-2014.

Huynh Quang Minh, Department of Power system, University of Technology, VNU-HCM, Vietnam (e-mail: hqminh@hcmut.edu.vn).

Nguyen Van Liem, Department of Power system, University of Technology, VNU-HCM, Vietnam (e-mail: nvliem@hcmut.edu.vn).

\section{INTRODUCTION}

Tn recent years, the use of renewable energy resources is more and more increased due to the increasing need for energy and the shortage of traditional energy sources in the near future [1].

Many research and development in wind energy conversion system (WECS) have shown their excellent potential for remote areas located so far from power stations and distribution networks which are uneconomical to install [2]. A practical approach for stand-alone power generation is to use a variable speed permanent magnet synchronous generator (PMSG) driven wind turbine to create an autonomous system. PMSGs are used widely in stand-alone WECS because of its advantages: higher reliability, less maintenance and more effectiveness. Besides, it is suitable for variable speed operation, which provides $10-15 \%$ higher energy output, lower mechanical stress and less power fluctuation compared with constant speed operation [3].

In order to take benefit from variable speed WECS, we must develop a system capable of extracting maximum power from the wind at different conditions. There are two type of maximum power point tracking (MPPT) method for wind turbine: indirect and direct. Indirect methods are based on the knowledge of the generator's power characteristic, which is usually not available with a high degree of accuracy and also changes with rotor aging and require wind speed measurement [4]. On the other hand, direct methods are independent from the knowledge of the generator curve, and the operating point is independent of climatic conditions [5]. In this paper, three direct searching MPPT controllers for stand-alone variable speed PMSG driven wind turbine are compared in extracting maximum 
power from wind without any knowledge about generator's characteristic or ambient condition.

\section{PMSG DRIVEN WIND TURBINE}

\subsection{Wind aerodynamic}

Mechanic power of a wind turbine can be expressed in terms of the air density $\rho$, the blade radius $R_{\text {blade }}$, and is the wind speed $v_{\text {wind }}[6]$ :

$$
P_{m}=0.5 C_{p} \rho \pi R_{\text {blade }}^{2} v_{\text {wind }}^{3}
$$

where $C_{p}$ is the power coefficient. This coefficient is also known as Betz limit. It can be expressed in terms of reduced velocity $\lambda$ and blade angle $\beta$. If $\omega$ is the rotor speed, the reduced speed $\lambda$ is defined:

$$
\lambda=\omega R_{\text {blade }} / v_{\text {wind }}
$$

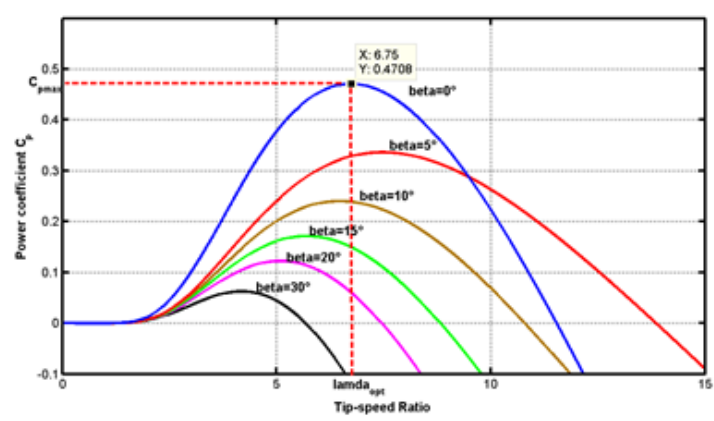

Fig. 1. $C_{p}$ vs. $\lambda$, for various pitch angles $\beta$.

A generic equation is used to model the power coefficient $C_{p}=C_{p}(\lambda, \beta)$, based on the modeling turbine characteristics described in [6]:

$$
C_{p}(\lambda, \beta)=0.5\left(98 / \lambda_{i}-0.4 \beta-5\right) e^{-16.5 / \lambda_{i}}
$$

where:

$$
\lambda_{i}=1 /\left[1 /(\lambda+0.08 \beta)-0.035 /\left(\beta^{3}+1\right)\right](4)
$$

The characteristic function $C_{p}$ vs. $\lambda$, for various values of the pitch angle $\beta$, is illustrated in Fig. 1. The maximum value of $C_{p}$ is achieved for $\beta=0^{\circ}$. This particular value $\lambda_{\text {opt }}$ results in the point of optimal efficiency where the wind turbine captures the maximum power [7]. In this work, a typical small-sized three-bladed horizontal-axis wind turbine generator without pitch control is considered, so $\beta=0^{\circ}$ at all times.

If the speed ratio is maintained at its optimal value $\lambda_{\text {opt }}$, the power coefficient is at its maximum value $C_{p M}=C_{p}\left(\lambda_{o p t}\right)$, the maximum power extracted from the wind turbine will be:

$$
P_{m_{-} \text {opt }}=0.5 C_{p M} \rho \pi R_{\text {blade }}^{2} v_{\text {wind }}^{3}
$$

On the other hand, the speed ratio assumed to be maintained at the optimum value, we obtain the optimum speed rotor:

$$
\begin{aligned}
& \lambda_{\text {opt }}=\omega_{\text {opt }} R_{\text {blade }} / v_{\text {wind }} \\
& \rightarrow \omega_{o p t}=\lambda_{\text {opt }} v_{\text {wind }} / R_{\text {blade }}
\end{aligned}
$$

Thus, for each wind speed $v_{\text {wind }}$, there is an optimal rotor speed $\omega_{\text {opt }}$ which made a maximum power recovered from the wind (Fig. 2).

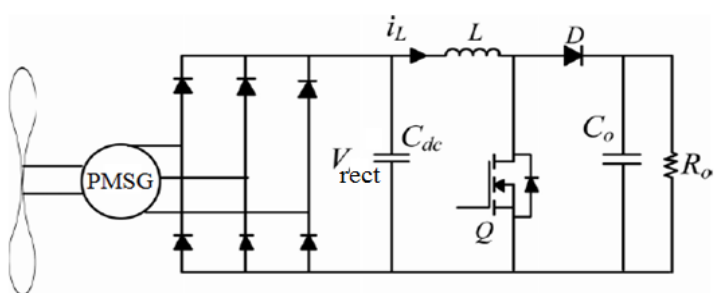

Fig. 3. PMSG driven wind turbine configuration.

\subsection{Electrical system modeling}

The WECS incorporated in our scheme consists of a wind turbine coupled to a PMSG. Since the PMSG produces variable amplitude - variable frequency voltage, additional power electronic devices are required to meet power quality demand. A three-phase diode bridge rectifier is used for the AC/DC conversion. A boost converter (DC/DC) is used to vary the rotor speed by adjusting the converter's duty cycle.

The dynamic model of PMSG can be represented in the Park's system using these equations [8]:

$$
\begin{aligned}
& V_{d}=-R_{s} i_{d}-L_{d} d i_{d} / d t+\omega L_{q} i_{q} \\
& V_{q}=-R_{s} i_{q}-L_{q} d i_{q} / d t-\omega L_{d} i_{d}+\omega \lambda_{m}
\end{aligned}
$$

The expression of electromagnetic torque in the rotor is given by:

$$
\begin{aligned}
& T_{e}=3 / 2 p\left[\left(L_{d}-L_{q}\right) i_{q} i_{d}-\lambda_{m} i_{q}\right] \\
& \omega_{e}=\omega . p
\end{aligned}
$$

where $p$ is the number of pole pair, $\lambda_{m}$ is the magnetic flux, $L_{d}$ is the direct axis inductance, $L_{q}$ is the inductance in quadrature, $R_{s}$ is the stator resistance and $\omega$ is the electrical angular frequency.

If the rotor is cylindrical, $L_{d} \approx L_{q} \approx L_{s}$ so:

$$
T_{e}=-1.5 p i_{q} \lambda_{m}
$$

Relationship between mechanical torque and electromagnetic torque in a wind turbine:

$$
T_{m}-T_{e}=J . d \omega / d t
$$


where $J$ is the inertia of the wind turbine.

In PMSG wind generation systems, the output current and voltage are proportional to the electromagnetic torque and rotor speed, respectively [9]:

$$
\begin{aligned}
& T_{e}=k_{T} I_{a} \\
& E=k_{e} \omega
\end{aligned}
$$

Where $I_{a}$ is the stator current. On the other hand:

$$
E^{2}=V_{W T}^{2}+\left(I_{a} L_{s} \omega\right)^{2}
$$

$V_{W T}$ is the generator phase voltage and $L_{s}$ is the inductance of the generator.

From (14), (15) we have:

$$
\omega \propto V_{W T} \rightarrow d \omega / d t \propto d V_{W T} / d t
$$

Thus, in a variable speed PMSG driven wind turbine, we can vary the output voltage $V_{W T}$ of the generator to change the rotor speed $\omega$. If we can control our system to work at the optimal rotor speed $\omega_{\text {opt }}$, maximum power will be extracted from the wind turbine.

\section{MPPT ALGORITHMS}

\subsection{Conventional Perturb \& Observe $(P \& O)$ MPPT controller}

In the field of MPPT for wind energy, the P\&O algorithm is a very popular method because of its simplicity and easy implementation. The main idea is the perturbation of rotor speed and takes reaction to reach the maximum power point (MPP). If the variation of the rotor speed increases the power extracted, the next variation will be kept in that direction. Conversely, if the variation of the rotor speed decreases the power extracted, the next variation will be reversed [10].

However, this method has its own negative points. The response to wind speed change is extremely slow, especially for large inertia wind turbines [11], [12]. Rapidly fluctuating character of wind supply makes the situation even worse.

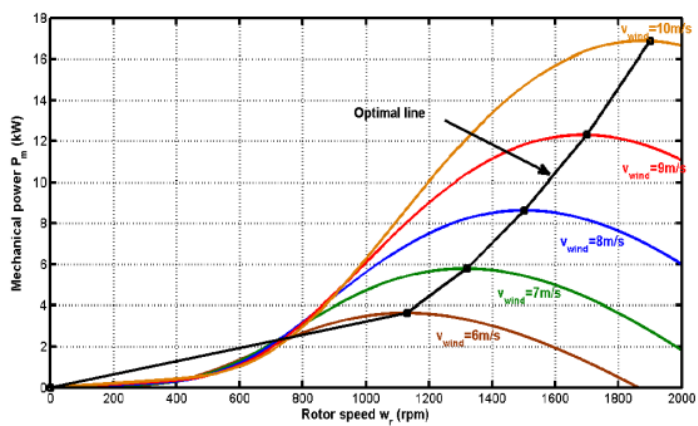

Fig. 2. Mechanic power vs. rotor speed.
Oscillation around the MPP is also another inevitable disadvantage. All these drawbacks can significantly lower MPPT efficiency and may cause oscillation in the system [13].

\subsection{Modified $P \& O M P P T$ controller}

The modified $\mathrm{P} \& \mathrm{O}$ method is based on the inductor's current of the boost converter [14]:

$$
i_{L}=V_{\text {rec }} / Z_{D C}
$$

where $Z_{D C}$ is the input impedance of the boost converter.

From (1) we can conclude that:

$$
T_{m} \propto v_{\text {wind }}^{3}
$$

From (12), (16) and (18) we have:

$$
d V_{\text {rec }} / d t \propto v_{\text {wind }}^{3}
$$

On the other hand, from (17):

$$
d V_{\text {rec }} / d t \propto i_{L}
$$

We can see that the slope of the rectifier's voltage is more sensitive with the change of wind speed $\left(v_{\text {wind }}^{3}\right)$ than the change of the inductor's current $\left(i_{L}\right)$. If the perturbation makes this current vary, the slope of the voltage will vary slightly to observe the power of system. On the other hand, when wind speed changes, the slope of the voltage will change rapidly, so we can easily recognize the change of wind speed and system's perturbation. Via this variable, we can observe easily any change of wind speed in our system. If there is no variation of wind, the slope is small and lower than a threshold while wind speed varies fast, the slope is remarkable [14].

The modified algorithm uses the inductor's current as a perturbation variable. The rectifier's voltage is not controlled, it is observed and the step size of the algorithm is based on its variation when wind speed. The modified method works in 2 modes: Conventional $\mathrm{P} \& \mathrm{O}$ in low variation wind condition, in which use adaptive step size with the change of power and the $2^{\text {nd }}$ mode is a predictive mode in high variation wind condition. This mode will make the system work near the MPP when wind speed changes by using the slope of the rectifier's voltage to decide the direction and the step size of the next perturbation. When our system reach the MPP, the slope is very small $(\approx 0)$, this will also reduce the oscillation of the controller.

\subsection{Fuzzy MPPT controller}

The fuzzy MPPT algorithm is based on the relationship between wind power and rotor speed at the MPP: 
$d P / d \omega=0$

Applying the chain rule, we have:

$$
d P / d \omega=(d P / d V) \cdot(d V / d \omega)=0
$$

In a PMSG, rotor speed is proportional to the generator phase voltage, so:

$$
d V / d \omega>0
$$

Then:

$$
d P / d \omega=0 \Rightarrow d P / d V=0
$$

On the MPP, we have $d P / d V=0$. If we are in the up-hill region $(d P / d V>0)$, we should increase the voltage to reach the MPP. If we are in the down-hill region $(d P / d V<0)$, we should decrease the voltage to reach the MPP. Thus, whenever wind speed or load demand change, wind turbine power or wind turbine output voltage will vary, so the controller can recognize these change and react to reach the new MPP.

To implement this algorithm in a fuzzy controller, we need two inputs: change in wind turbine power and its derivative, output is the change of duty cycle of the boost converter.

\section{SIMULATION AND RESULTS}

\subsection{Tested system and initial conditions}

The modified $\mathrm{P} \& \mathrm{O}$ controller is designed to track the MPP of the stand-alone WECS whose inputs are wind turbine power, inductor's current and rectifier's voltage, and output is duty ratio of the boost converter. The control algorithms are implemented and tested in Simulink/Matlab (Fig. 4).

Wind speed is varied within 12 seconds to test our controllers in fast climatic conditions (Fig. 5, $6)$.

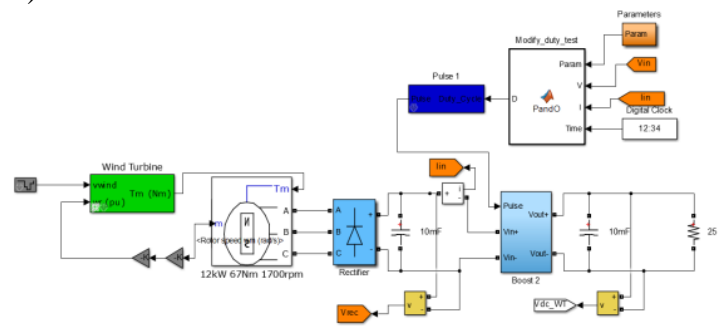

Fig. 4. Simulation in MATLAB/Simulink.

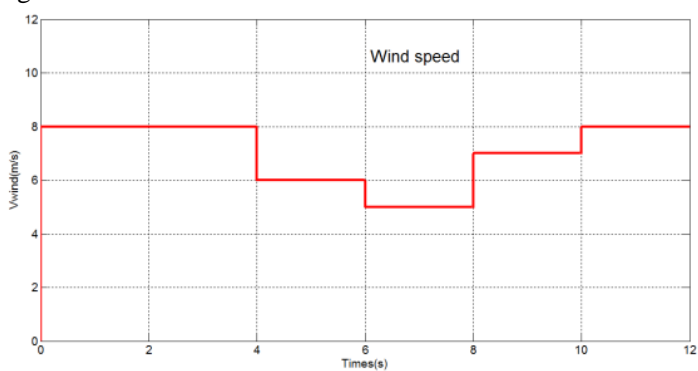

Fig. 5. Wind speed.

(8)

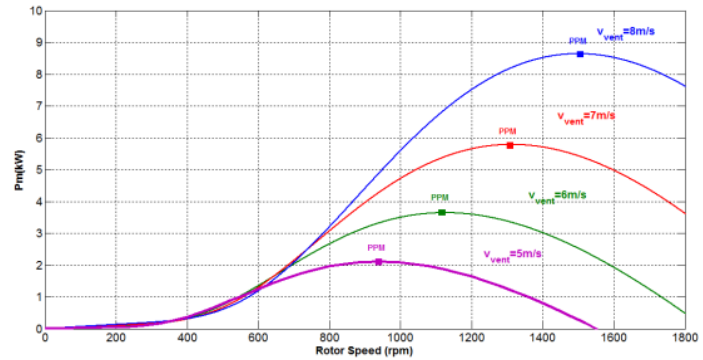

Fig. 6. Power vs. rotor speed curves.

\subsection{Result and discussion}

We can see that when wind speed changes, the power extracted from our WECS is maximized near the theory line. The modified controllers are stable at MPP and extract more power than the conventional one (Fig. 7, 8).

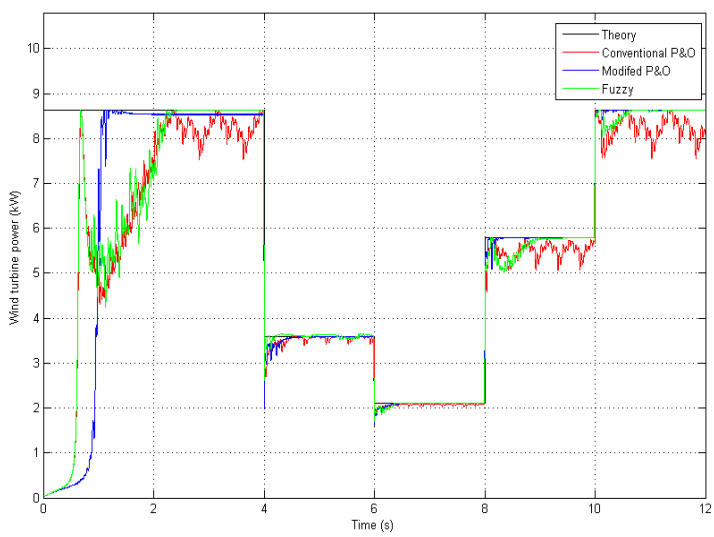

Fig. 7. Power extracted.

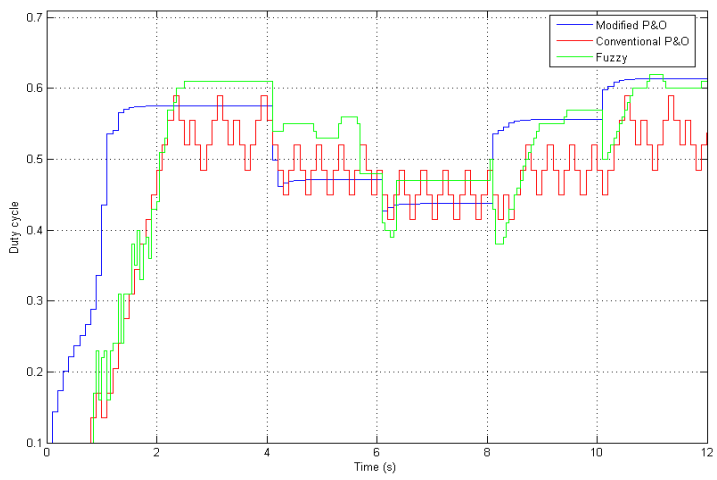

Fig. 8. Duty cycle.

Zoom into the power extracted with wind speed at $5 \mathrm{~m} / \mathrm{s}$ and $7 \mathrm{~m} / \mathrm{s}$ (Fig. 9, 10), we can see that the modified methods extract more power compare with conventional $\mathrm{P} \& \mathrm{O}$, and there's no oscillation at the MPP. 


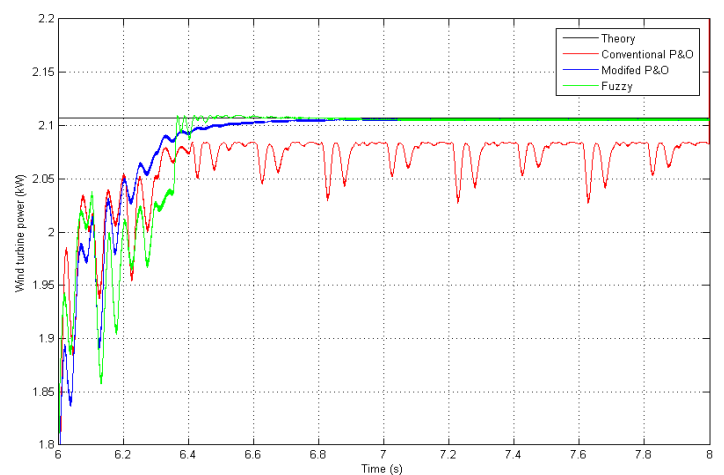

Fig. 9. Power extracted at $v_{\text {wind }}=5 \mathrm{~m} / \mathrm{s}$.

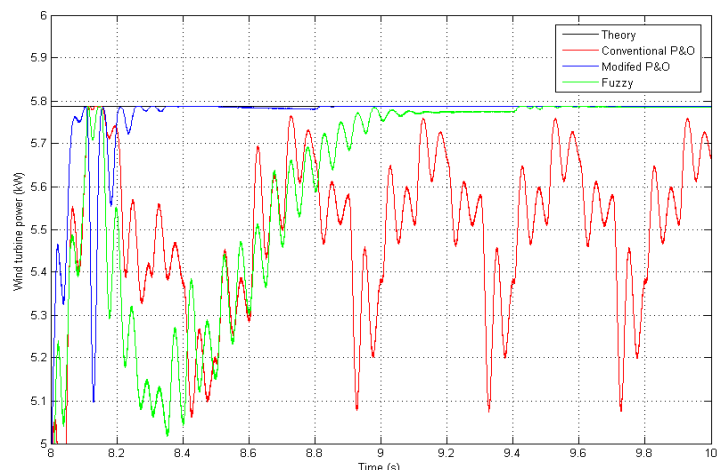

Fig. 10. Power extracted at $v_{\text {wind }}=7 \mathrm{~m} / \mathrm{s}$.

The modified controllers has find out whenever the wind speed increases or decreases and reacts rapidly with this change to move to the new MPP while original $\mathrm{P} \& \mathrm{O}$ still searching for the new MPP (Fig. 11, 12).

We can see that two modified controllers work well to track the MPP when wind speed change rapidly and extract more power than the conventional $\mathrm{P} \& \mathrm{O}$ controller.

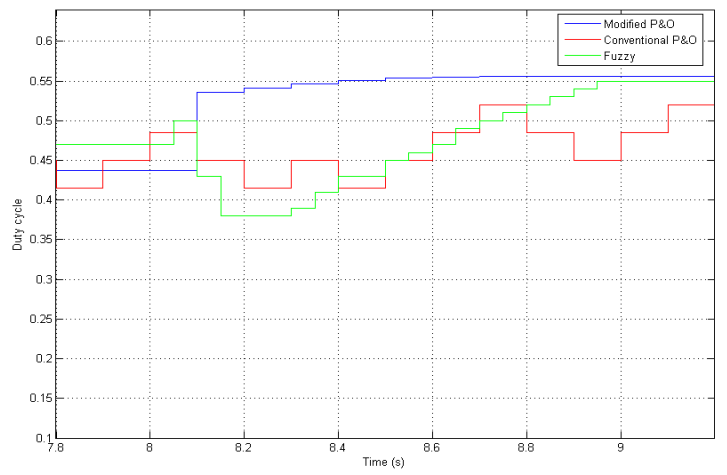

Fig. 11. Detection of increasing wind speed.

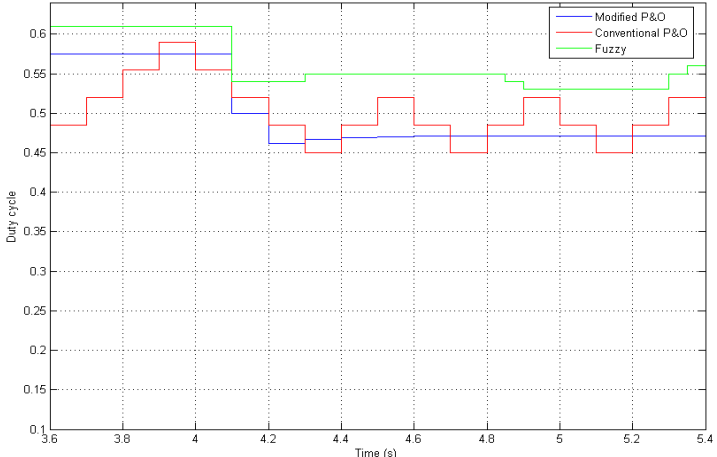

Fig. 12. Detection of decreasing wind speed.

\section{CONCLUSION}

In this paper, three direct MPPT methods for WECS are compared. Without information of wind speed or generator's power characteristic, control signals were generated to recover maximum power from the wind in fast climatic condition. Simulation result shows good behavior of the controllers to achieve the MPP and avoid the disadvantages of conventional $\mathrm{P} \& \mathrm{O}$ method.

\section{REFERENCES}

[1]Kumar, Yogesh, et al. "Wind energy: trends and enabling technologies." Renewable and Sustainable Energy Reviews 53 (2016): pp. 209-224.

[2] H. Li, Z. Chen, "Overview of generator topology for wind turbines", IETProc. Renewable Power Generation, vol. 2, no. 2, pp. 123-138, 2008.

[3]Pellegrino, Gianmario, et al. The Rediscovery of Synchronous Reluctance and Ferrite Permanent Magnet Motors: Tutorial Course Notes. Springer, 2016.

[4]J. Kaldellis, K. Kavadias, and P. Koronakis, "Comparing wind and photovoltaic stand-alone power systems used for the electrification of remote consumers", Renewable and Sustainable Energy Reviews, vol. 11, no. 1, pp. 57-77, 2007.

[5] Sarkar, Joydeep, and Shridhar S. Khule. "A study of MPPT schemes in PMSG based wind turbine system." Electrical, Electronics, and Optimization Techniques (ICEEOT), International Conference on. IEEE, 2016.

[6]J.F. Manwell, J.G. McGowan and A.L. Rogers. "Wind Energy Explained: Theory, Design and Application", John Wiley \& Sons, 2009.

[7]de Freitas, Tiara RS, Paulo JM Menegáz, and Domingos SL Simonetti. "Rectifier topologies for permanent magnet synchronous generator on wind energy conversion systems: A review". Renewable and Sustainable Energy Reviews 54 (2016): pp. 1334-1344.

[8]B. Wu, Y. Lang, N. Zargari and S. Kouro, "Power Conversion and Control of Wind Energy Systems", John Wiley and Sons, 2011.

[9]Q. Huynh, F. Nollet, N. Essounbouli, and A. Hamzaoui, "Fuzzy control of variable speed wind turbine using permanent magnet synchronous machine for stand-alone system", Sustainability in Energy and Buildings: Proceedings of the 3rd International Conference in 
Sustainability in Energy and Buildings (SEB 11), vol. 12. Springer Verlag, pp. 31, 2012.

[10] Sahin, P., R. Resmi, and V. Vanitha. "PMSG based standalone wind electric conversion system with MPPT." Emerging Technological Trends (ICETT), International Conference on. IEEE, 2016.

[11]Tiwari, Ramji, and N. Ramesh Babu. "Fuzzy logic based MPPT for permanent magnet synchronous generator in wind energy conversion system." IFAC - Papers On Line 49.1 (2016): pp. 462-467.

[12]A. M. Knight and G. E. Peters, "Simple wind energy controller for an expanded operation range", IEEE Trans. Energy Convers., vol. 20, no. 2, pp. 459-466, 2005.

[13] Yuanye Xia, Khaled H. Ahmed, and Barry W. Williams, "A new maximum power point tracking technique for permanent magnet synchronous generator based wind energy conversion system", IEEE Transactions on Power Electronics, vol. 26, 2011.

[14]K. Padmanabham, K. Balaji Nanda Kumar Reddy, “A new MPPT control algorithm for wind energy conversion system", International Journal of Engineering Research \& Technology, vol.4 - Issue 03, 2015.
Huynh Quang Minh received the B.E. (2003), M.E. (2005) in Ho Chi Minh City University of Technology, VNU-HCM, VIETNAM, and D.E. (2013) degrees in electrical engineering from University of Reims Champagne-Ardenne, FRANCE.

$\mathrm{He}$ is a lecturer in Department of Power System, Faculty of Electrical \& Electronics Engineering, Ho Chi Minh City University of Technology, VNU-HCM. His Current interests include renewable energy for stand-alone system, maximum power point algorithm for wind and photovoltaic system.

Nguyen Van Liem received his BE in Electrical Engineering from Ho Chi Minh City University of Technology, VNU-HCM in 1986 and PhD in Electrical Engineering from The University of Western Australia in 2008. He is currently a lecturer of Ho Chi Minh City University of Technology, VNU-HCM. His research interests are in the fields of power systems modeling, analysis and control with particular reference to stability, FACTS application and renewable energy.

\title{
So sánh các giải thuật tìm kiếm điểm làm việc cực đại cho tua bin gió sử dụng máy phát đồng bộ nam châm vĩnh cửu
}

\author{
Huỳnh Quang Minh, Nguyễn Văn Liêm
}

\begin{abstract}
Tóm tắt— Năng lương gió được sử dụng ngày càng nhiều trên thế giới. Thuật toán dò tìm điểm làm việc cực đại cho tua bin gió rất cần thiết để có thể lấy được tối đa năng lượng từ gió. Nhiễu loạn và quan sát là giải thuật đơn giản và được sử dụng nhiều cho mục đích này. Tuy nhiên, giải thuật này có những nhược điểm như dao động quanh điểm làm việc cực đại và dò tìm sai khi tốc độ gió thay đồi nhanh. Có rất nhiều công trình nghiên cứu để giải quyết những hạn chế này. Trong bài báo này, giải thuật nhiễu loạn và quan sát truyền thống, nhiễu loạn và quan sát cải tiến và điều khiển mờ cho tua bin gió sử dụng máy phát đồng bộ nam châm vĩnh cửu sẽ được so sánh với nhau về độ phức tạp, tốc độ đáp ứng và khả năng thu công suất.
\end{abstract}

Tù $\boldsymbol{k h o ́}$ - - Tua bin gió, máy phát đồng bộ nam châm vĩnh cửu, dò tìm điểm làm việc công suất cực đại, nhiễu loạn và quan sát, giải thuật cải tiến, điều khiển mờ. 